\title{
RAFT Synthesis and Self-Assembly of Free-Base Porphyrin Cored Star Polymers
}

\author{
Lin Wu, ${ }^{1}$ Ronan McHale, ${ }^{1}$ Guoqiang Feng, ${ }^{2}$ and Xiaosong Wang ${ }^{1,3}$ \\ ${ }^{1}$ Department of Colour Science, School of Chemistry, University of Leeds, Leeds LS2 9JT, UK \\ ${ }^{2}$ Laboratory of Pesticide and Chemical Biology, Ministry of Education, Central China Normal University, Wuhan 430079, China \\ ${ }^{3}$ Department of Chemistry and Institute of Nanotechnology, University of Waterloo, Waterloo, Canada N2L $3 G 1$
}

Correspondence should be addressed to Xiaosong Wang, xiaosong.wang@uwaterloo.ca

Received 25 March 2011; Accepted 11 May 2011

Academic Editor: Peng He

Copyright (c) 2011 Lin Wu et al. This is an open access article distributed under the Creative Commons Attribution License, which permits unrestricted use, distribution, and reproduction in any medium, provided the original work is properly cited.

\begin{abstract}
Reversible addition fragmentation chain transfer (RAFT) synthesis and self-assembly of free-base porphyrin cored star polymers are reported. The polymerization, in the presence of a free-base porphyrin cored chain transfer agent (CTA-FBP), produced porphyrin star polymers with controlled molecular weights and narrow polydispersities for a number of monomers including $N$, $N$-dimethylacrylamide (DMA) and styrene (St). Well-defined amphiphilic star block copolymers, P-(PS-PDMA) ${ }_{4}$ and P-(PDMA$\mathrm{PS})_{4}$ (P: porphyrin), were also prepared and used for self-assembly studies. In methanol, a selective solvent for PDMA, spherical micelles were observed for both block copolymers as characterized by TEM. UV-vis studies suggested star-like micelles were formed from P-(PS-PDMA) ${ }_{4}$, while P-(PDMA-PS $)_{4}$ aggregated into flower-like micelles. Spectrophotometric titrations indicated that the optical response of these two micelles to external ions was a function of micellar structures. These structure-related properties will be used for micelle studies and functional material development in the future.
\end{abstract}

\section{Introduction}

The controlled organization of functional dyes, such as porphyrins, into polymer supramolecular systems has numerous potentially interesting material applications [1]. Porphyrin containing biological systems, where the dye usually works in aggregated structures, offer insights to these possibilities. Both the chemical structure of the dye and its cooperative interaction with other molecules accomplishes various complex functions such as photosynthesis and electron transfer [2].

Several porphyrin polymers have been synthesized [317]. Micellization of these polymers offers the opportunity to organize the nanostructure of dyes in solution. For example, through the self-assembly of a porphyrin-centered amphiphilic star poly(oxazoline) in water/DMF, Jin observed vesicular aggregates [12]. Similar morphology aggregated from monofunctionalized metalloporphyrin polystyrene was also reported by de Loss et al. [14]. Despite these interesting discoveries, the self-assembly behaviour of porphyrin polymers is far from being understood and further research is required. We, therefore, are interested in the synthesis of well-defined free-base porphyrin polymers for self-assembly studies in an attempt at exploring porphyrin chemistry in polymer supramolecular assemblies.

Among various options, living radical polymerization, which can be carried out under mild conditions and is compatible with a wide range of monomers, represents the best choice for this study [14-17]. As a matter of fact, several groups have explored similar syntheses using nitroxide mediated polymerization (NMP) [15] and atom transfer radical polymerization (ATRP) [14-17]. Zimmerman reported that NMP could be used to prepare porphyrin cored star copolymers. However, the resulting polymers usually had broad polydispersities and multimodal molecular weight distributions [15]. ATRP catalyzed by transition metals has proven to be successful in the synthesis of well-defined porphyrin polymers. However, its use has been limited to metal ion ( $\mathrm{Zn}$ (II) [16], Pd(II) [17]) coordinated porphyrin initiators and thus the production of metal complexed polymers. Attempts to synthesize polymers containing free-base porphyrin using ATRP was unsuccessful, because $\mathrm{Cu}$ (II) (formed by the $\mathrm{Cu}(\mathrm{I}$ ) 
catalyst) will preferentially insert into the porphyrin core $[14,16]$. Although metalloporphyrin polymers possess many interesting properties for applications, such as catalysis, light harvesting, oxygen transportation [3-17], and so on, other increasingly studied applications, such as sensors [18], prefer free-base porphyrin polymers. In our self-assembly research, free-base porphyrin polymers with optical sensitivity to external ions will be useful in probing aggregate structures.

Reversible addition fragmentation chain transfer (RAFT) [19] provides a distinct advantage in the synthesis of freebase porphyrin polymers. Not only is RAFT a metal-free living radical system, it also has proven over years of intensive research to be compatible with a wide range of monomers, thus offering flexibility in molecular design [20-24]. Despite these advantages, the preparation of porphyrin polymers via RAFT has not yet been reported [25-33].

Herein, we report the synthesis of free-base porphyrin cored star (co) polymers using RAFT polymerization. The polymerization was initiated by AIBN and mediated by a free-base porphyrin cored RAFT agent (CTA-FBP). Welldefined free-base porphyrin cored star homopolymers and amphiphilic block copolymers were successfully produced. Following the synthetic work, the self-assembly behaviours of the porphyrin cored amphiphilic star block copolymers were explored and the optical properties of the porphyrin stimulated by external ions were used to probe the structures of the aggregates.

\section{Experimental}

2.1. Materials. 5, 10, 15, 20-tetrakis(4-hydroxyphenyl)$21 \mathrm{H}, 23 \mathrm{H}$-porphine (THPP), 4-dimethylaminopyridine, and $\mathrm{N}, \mathrm{N}^{\prime}$-Dicyclohexylcarbodiimide (DCC) were purchased from Aldrich and used as received. S-1-Dodecyl-S'-( $\alpha, \alpha^{\prime}-$ dimethyl- $\alpha^{\prime \prime}$-acetic acid)trithiocarbonate (CTA1) was synthesized according to a reported procedure [20-24]. 2, 2' Azobisisobutyronitrile (AIBN, 99\%, Aldrich) was purified by recrystallization from methanol. All monomers were obtained from Aldrich and passed through a short basic alumina column to remove radical inhibitors before use. All solvents and other chemicals were purchased from Aldrich or Alfa Aesar and used as received unless otherwise stated. Spectrophotometric grade methanol was used for micelle preparation and optical behavior studies.

2.2. Characterization. Both ${ }^{1} \mathrm{H} \quad(400 \mathrm{MHz})$ and ${ }^{13} \mathrm{C}$ $(100 \mathrm{MHz})$ NMR spectra were recorded on a Bruker 400 UltraShield spectrometer at room temperature $\left(\sim 20^{\circ} \mathrm{C}\right)$ with $\mathrm{CDCl}_{3}$ used as solvent, unless otherwise stated. Molecular weight distributions of the polymer products were recorded using gel permeation chromatography (GPC) at ambient temperature using a system equipped with a Polymer Laboratories $5.0 \mu \mathrm{m}$-bead-size guard column (50 $\times 7.5 \mathrm{~mm})$ and two Polymer Laboratories PLgel $5 \mu \mathrm{m}$ MIXED-C columns (Molecular weight range of 2,000,000$500 \mathrm{~g} / \mathrm{mol}$ ) with a differential refractive index detector (Shodex, RI-101). Unless otherwise stated, tetrahydrofuran containing triethylamine $(5 \%, \mathrm{v} / \mathrm{v})$ and 2,6-di-tert-butyl4 -methylphenol $(0.08 \mathrm{~g} / \mathrm{L})$ was used as an eluent at a flow rate of $1 \mathrm{~mL} / \mathrm{min}$. Toluene was used as a flow rate marker. Poly(styrene) in the range of 7,500,000-580 $\mathrm{g} / \mathrm{mol}$ was used as the standard for calibration. Dynamic light scattering (DLS) was performed at room temperature on a Brookhaven light scattering system (BI-200SM Laser Light Scattering Goniometer) with a BI-APD detector using a He-Ne laser at $633 \mathrm{~nm}$. The detector angle was set at $90^{\circ}$. Transmission electron microscopy (TEM) images were obtained on a JEOL 1200EX Transmission Electron Microscope with an acceleration voltage of $80 \mathrm{kV}$. For TEM sample preparation, a drop of micellar solution was deposited onto a carbon coated copper grid. The solution was then drained off using a piece of filter paper. All the micelles were negatively stained using uranyl acetate $(2 \%)$ except $\mathrm{Zn}^{2+}$ coordinated samples. UV-vis absorption spectra were recorded at room temperature on a Jasco V-530 spectrophotometer using a quartz cell of $1 \mathrm{~cm}$ path length. The samples were scanned in the range of $800-250 \mathrm{~nm}$, and the scanning speed was set at $4000 \mathrm{~nm} / \mathrm{min}$. Spectrophotometric grade methanol was used as background. Fluorescence measurements were recorded at room temperature on a Jobin Yvon-SPEX FluoroMax-3 fluorometer with excitation wavelength set at $410 \mathrm{~nm}$ and with $1 \mathrm{~nm}$ of increment and $0.1 \mathrm{~s}$ of integration time. The slits for both excitation and emission were set at $2 \mathrm{~nm}$.

2.3. Synthesis of CTA-FBP. A mixture of S-1-dodecyl-S'$\left(\alpha, \alpha^{\prime}\right.$-dimethyl- $\alpha^{\prime \prime}$-aceticacid) (trithiocarbonate CTA1, $605 \mathrm{mg}, 1.66 \mathrm{mmol}$ ), 5, 10, 15, 20-tetrakis(4-hydroxyphen$\mathrm{yl})-21 \mathrm{H}, 23 \mathrm{H}$-porphine $(270 \mathrm{mg}, 0.4 \mathrm{mmol})$ and 4 -dimethylaminopyridine (DMAP, $21 \mathrm{mg}, 0.17 \mathrm{mmol}$ ) in dichloromethane $(25 \mathrm{~mL})$, and DMF $(0.8 \mathrm{~mL})$ was stirred at $10^{\circ} \mathrm{C}$ under nitrogen atmosphere. $N, N^{\prime}$-dicyclohexylcarbodiimide (DCC, $350 \mathrm{mg}, 1.69 \mathrm{mmol}$ ) was added in portions. The resulting mixture was stirred at room temperature for 24 hours and then poured into water $(20 \mathrm{~mL})$. The product was then extracted into dichloromethane $(30 \mathrm{~mL} \times 3)$. The combined organic phase was dried over $\mathrm{Na}_{2} \mathrm{SO}_{4}$ and filtered, with the solvent subsequently removed under reduced pressure. The crude product was purified by column chromatography (eluted with dichloromethane) to afford $335 \mathrm{mg}$ CTA-FBP as a purple solid in $41 \%$ yield. ${ }^{1} \mathrm{H}$ NMR $\left(400 \mathrm{MHz}, \mathrm{CDCl}_{3}\right)$ : $\sigma 8.86(\mathrm{~s}, 8 \mathrm{H}$, pyrrole $\mathrm{H}), 8.21(\mathrm{~d}, J=8.33 \mathrm{~Hz}, 8 \mathrm{H}, \operatorname{ArH})$, $7.51(\mathrm{~d}, J=8.58 \mathrm{~Hz}, 8 \mathrm{H}, \operatorname{ArH}), 3.40(\mathrm{t}, J=7.35 \mathrm{~Hz}, 8 \mathrm{H}$, $\left.4 \mathrm{CH}_{2} \mathrm{~S}\right), 2.00\left(\mathrm{~s}, 24 \mathrm{H}, 8 \mathrm{CH}_{3}\right), 1.75\left(\mathrm{~m}, 8 \mathrm{H}, 4 \mathrm{CH}_{2}\right), 1.44$ $\left(\mathrm{m}, 8 \mathrm{H}, 4 \mathrm{CH}_{2}\right), 1.20-1.34(\mathrm{~m}, 64 \mathrm{H}), 0.81(\mathrm{t}, J=7.11 \mathrm{~Hz}$, $\left.12 \mathrm{H}, 4 \mathrm{CH}_{3}\right),-2.86$ (br s, $\left.2 \mathrm{H}, 2 \mathrm{NH}\right) .{ }^{13} \mathrm{C}$ NMR $(100 \mathrm{MHz}$, $\left.\mathrm{CDCl}_{3}\right): \sigma 172.11,150.95,139.71,135.22,119.87,119.19$, $55.95,37.24,31.85,29.61,29.58,29.53,29.45,29.29,29.12$, $28.98,27.89,25.46,22.63,14.09$.

2.4. Typical RAFT Polymerization Procedure. All polymerizations using CTA-FBP as chain transfer agent were carried out with AIBN as an initiator in a degassed and sealed tube. A representative example for the polymerization of DMA is described as follows. A stock solution of $10 \mathrm{mM}$ 


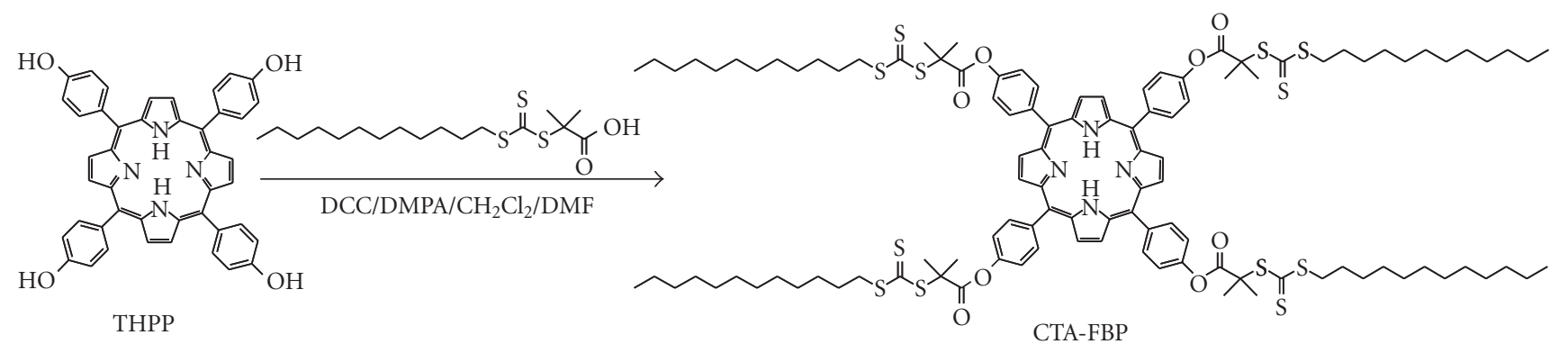

SCHEME 1: Synthesis of porphyrin cored RAFT agent (CTA-FBP).

AIBN in toluene was first prepared. An aliquot $(100 \mu \mathrm{L})$ of the AIBN solution was taken and transferred into a tube containing CTA-FBP $(10.3 \mathrm{mg}, 0.005 \mathrm{mmol})$ and monomer $(2 \mathrm{mmol})$. The solution was then sealed with a suba-seal and degassed with three freeze-thaw cycles, before back filling with nitrogen. The reaction mixture was immersed into a preheated oil bath at $65^{\circ} \mathrm{C}$ for a specified time. The polymer products were precipitated by dropwise addition of the reaction mixture to diethyl ether. The precipitates were filtered off, washed with diethyl ether, and dried in a vacuum. Final products were characterized by ${ }^{1} \mathrm{H}$ NMR and gel permeation chromatography (GPC). The procedure for the synthesis of amphiphilic block copolymer was the same except using the presynthesized star homopolymer as macroCTA.

2.5. Micellization of Porphyrin Star Block Copolymers. Micelles were prepared by the following method: to porphyrin cored star block copolymers of P-(PDMA $\left.{ }_{96}-\mathrm{PS}_{33}\right)_{4}$ or P$\left(\mathrm{PS}_{34}-\mathrm{PDMA}_{239}\right)_{4}(1 \mathrm{mg}), 10 \mathrm{~mL}$ methanol was added. The resulting mixture was gently heated to a clear solution before cooling down to room temperature.

2.6. UV-Vis Spectrophotometric Titration. Before titration, stock solutions of $0.025 \mathrm{M}, 0.25 \mathrm{M}$, and $2.5 \mathrm{M}$ aqueous $\mathrm{HCl}$ and $0.25 \mathrm{M} \mathrm{Zn}(\mathrm{OAc})_{2}$ in methanol were prepared. In the titration experiments, $2.5 \mathrm{~mL}$ of the porphyrin cored star block copolymer micelle solution in methanol $(0.1 \mathrm{mg} / \mathrm{mL})$ was added to a quartz cuvette. The porphyrin concentration was ca. $2 \times 10^{-6} \mathrm{M}$ in the P-(PDMA $\left.{ }_{96}-\mathrm{PS}_{33}\right)_{4}$ micelle solution and ca. $9 \times 10^{-7} \mathrm{M}$ in the $\mathrm{P}$ - $\left(\mathrm{PS}_{34}-\mathrm{PDMA}_{239}\right)_{4}$ micelle solution. For titration of $\mathrm{H}^{+}, \mu \mathrm{L}$ quantities of aqueous $\mathrm{HCl}$ were added to the polymer micelles, and the UV-vis absorbance was recorded until no changes persisted in the spectrum. Titration of $\mathrm{Zn}^{2+}$ was performed by the addition of $\mu \mathrm{L}$ quantities of $\mathrm{Zn}(\mathrm{OAc})_{2}$ solution in methanol to the polymer micelles until the final concentration of $\mathrm{Zn}^{2+}$ was $5 \times 10^{-4} \mathrm{M}$ in the cuvette.

2.7. Fluorescence Titration. $2.5 \mathrm{~mL}$ of the micelle solution $(0.1 \mathrm{mg} / \mathrm{mL})$ was added to a quartz cuvette. The emission spectrum of the micelle solution was then recorded with excitation at $410 \mathrm{~nm}$. Solid NaI was subsequently added to the solution ([NaI] in the solution ranged from $0.2 \mathrm{M}$ to1.6 M).
The emission spectrum of the micelle solution was recorded after each addition of NaI.

\section{Results and Discussion}

3.1. Synthesis of CTA-FBP. Depending on the chain transfer agent (CTA) structure, two approaches can be used for the synthesis of star polymers via RAFT polymerization: (1) propagation attached to the core and (2) propagation away from the core. These approaches are usually called Z-group and R-group approaches, respectively $[34,35]$. In general, side reactions such as star-star coupling and starchain coupling can occur in the synthesis of stars using the R-group approach, while, in theory, the Z-group approach should avoid this problem. A recent study, however, has shown the R-group approach to be the more efficient and controlled of the two [36], whilst star coupling side reactions put down due to chain transfer to polymer have also recently been observed in the Z-group approach [37]. Taking the above into account, we chose the R-group approach for the synthesis of our porphyrin cored star polymer. Therefore, the CTA-FBP as shown in Scheme 1 was synthesized by coupling 5, 10, 15, 20-tetrakis(4-hydroxyphenyl)-21H, $23 \mathrm{H}$ porphine (THPP) with $S$-1-dodecyl-S' $-\left(\alpha, \alpha^{\prime}\right.$-dimethyl- $\alpha^{\prime \prime}$ acetic acid)trithiocarbonate (CTA1) in the presence of DCC/DMAP.

THPP is a commercially available porphyrin derivative with four symmetrical hydroxyl groups, thus making it a very good candidate for the preparation of the four-arm CTA-FBP. CTA1 is a trithiocarbonate containing a C12 chain and a carboxylic acid group, and is suitable for the RAFT polymerization of a number of monomers [38]. Due to its easy preparation up to large scale and high efficiency in RAFT polymerizations [39-44], we used it to couple with THPP. The reaction was conducted in mixed solvents of dichloromethane and DMF. A small amount of DMF was added to aid the dissolution of THPP. The pure CTA-FBP was isolated by column chromatography as a purple solid in moderate yield. The ${ }^{1} \mathrm{H}$ NMR of CTA-FBP is shown in Figure 1 and the integral of all the peaks is in good agreement with the designed molecule.

3.2. RAFT Polymerization. The RAFT polymerization of $N, N$-dimethylacrylamide (DMA) was performed in bulk using CTA-FBP as chain transfer agent. The polymerization 


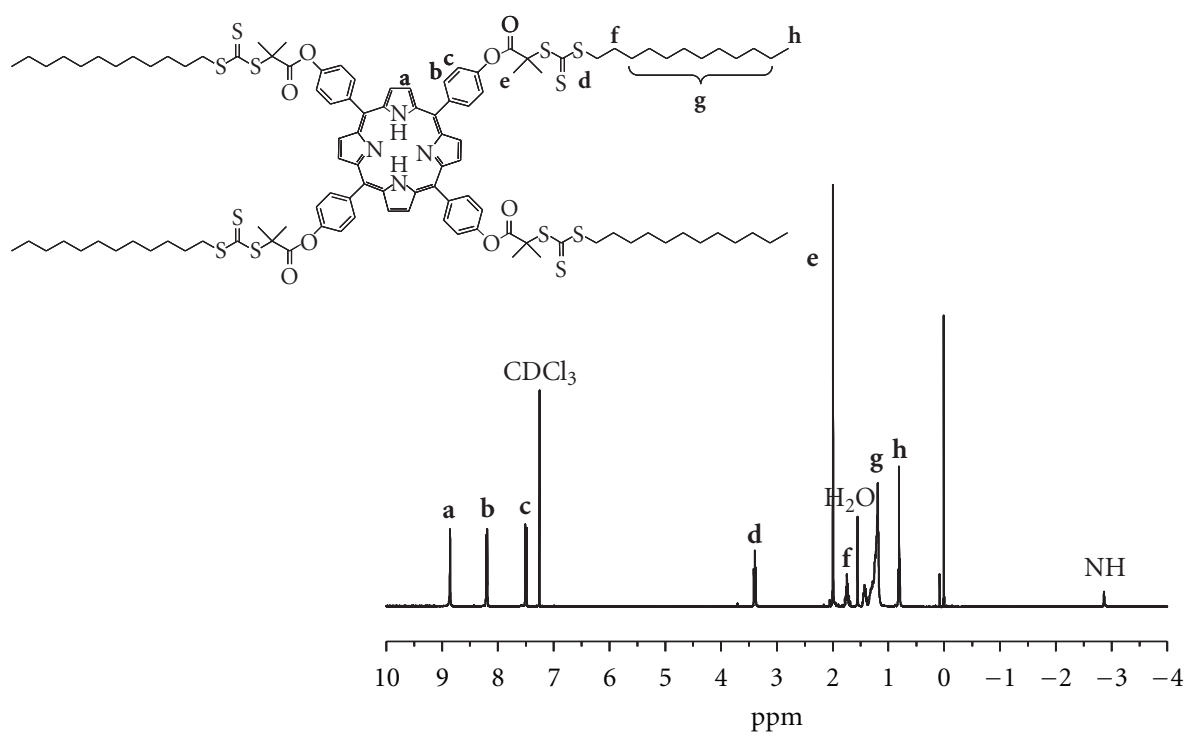

Figure 1: ${ }^{1} \mathrm{H}$ NMR of CTA-FBP in $\mathrm{CDCl}_{3}$.

TABLE 1: Synthesis of porphyrin cored PDMA star polymers using CTA-FBP as chain transfer agent initiated by $\mathrm{AIBN}$ at $65^{\circ} \mathrm{C}$.

\begin{tabular}{lccccc}
\hline Polymer products & M : CTA-FBP & Time $(h)$ & Conv. $(\%)$ & $M_{n}($ Calc. $)$ & $M_{n}(\mathrm{GPC})$ \\
\hline P-(PDMA) $)_{4}$ & $400: 1$ & 5 & 96 & 40100 & 23100 \\
P-(PDMA) $)_{4}$ & $600: 1$ & 5 & 94 & 57900 & 1.10 \\
P-(PDMA) $)_{4}$ & $800: 1$ & 5 & 90 & 74900 & 42500 \\
\hline
\end{tabular}

[Monomer] : [CTA-FBP]

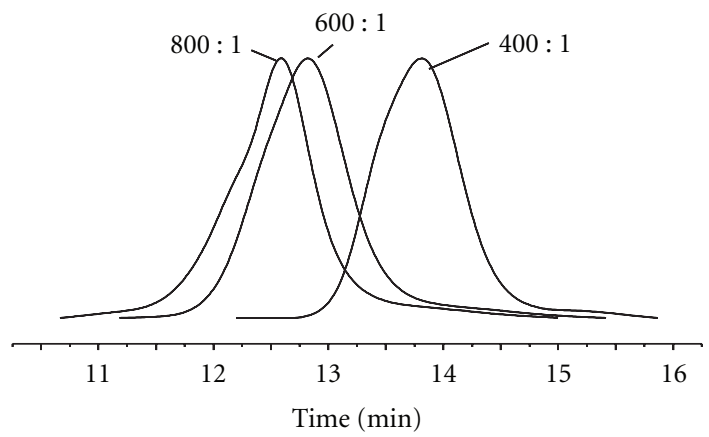

Figure 2: GPC traces for the polymers produced through RAFT of DMA at $65^{\circ} \mathrm{C}$ with different ratio of [DMA] : [CTA-FBP] from $400: 1$ to $800: 1$.

was initiated by AIBN at $65^{\circ} \mathrm{C}$ using a molar ratio of [CTA$\mathrm{FBP}]_{0} /[\mathrm{AIBN}]_{0}=1: 0.2$. Three experiments, with the ratios of monomer to CTA-FBP varied from $400: 1$ to $800: 1$, were carried out. In each case, high yields $(>90 \%)$ were achieved within 5 hours. The polymers were characterized by GPC, and the traces are illustrated in Figure 2. Monomodal molecular weight distributions were obtained, suggesting star-star coupling did not have deteriorating effect on the star polymer synthesis. Moreover, the GPC traces shifted to higher molecular weight proportional to the amount of monomer added, thus supporting a living/controlled polymerization process. The molecular weights and molecular weight distributions of

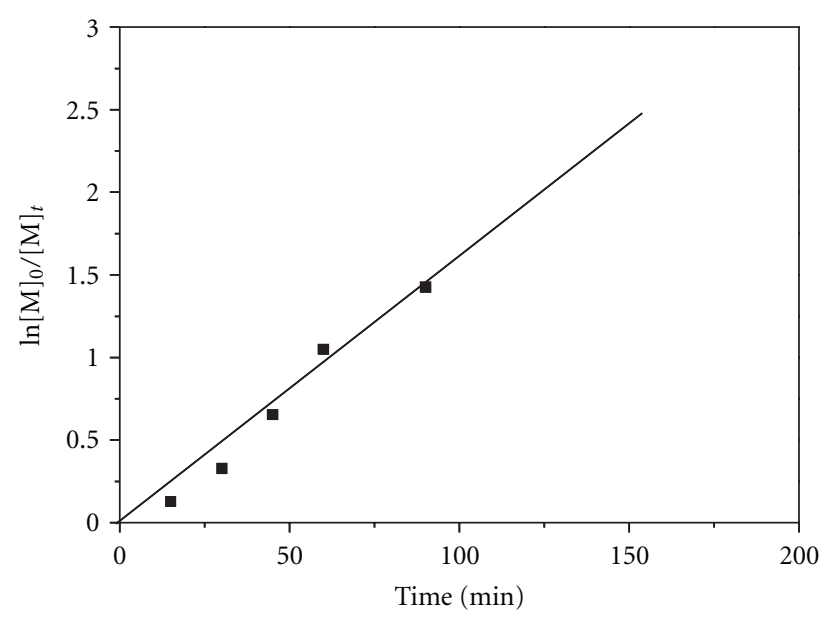

FIgURE 3: Kinetic plot for RAFT of DMA at $65^{\circ} \mathrm{C}$ with a ratio of $[\mathrm{DMA}]_{0}:[\mathrm{CTA}-\mathrm{FBP}]_{0}:[\mathrm{AIBN}]_{0}=400: 1: 0.2$.

the resultant polymers are summarized in Table 1. Although the target molecular weights are higher than those obtained, it is clear from the low polydispersities, as well as the fact that GPC often underestimates the molecular weights of star polymers due to architecture effects (see later), that the system is well controlled.

To test the livingness of the polymerization, a kinetic experiment was carried out at the ratio of $[\mathrm{DMA}]_{0} /[\mathrm{CTA}-$ $\mathrm{FBP}]_{0} /[\mathrm{AIBN}]_{0}=400: 1: 0.2$. The resultant data is illustrated 
TABLE 2: Synthesis of porphyrin cored star block copolymers using macro-CTA as chain transfer agent initiated by AIBN ${ }^{\mathrm{a}}$.

\begin{tabular}{|c|c|c|c|c|c|c|c|}
\hline Targeted block copolymers & Macro-CTA (PDI) & M & Time $(h)$ & Conv. $(\%)$ & Overall $M_{n}(\mathrm{GPC})$ & PDI & Block ratio \\
\hline $\mathrm{P}-(\mathrm{PDMA}-\mathrm{PS})_{4}$ & $\mathrm{P}-\left(\mathrm{PDMA}_{96}\right)_{4}(1.10)$ & St & 6 & 8.5 & 41200 & 1.13 & 96:33 (PDMA: PS) \\
\hline $\mathrm{P}-(\mathrm{PS}-\mathrm{PDMA})_{4}$ & $\mathrm{P}-\left(\mathrm{PS}_{34}\right)_{4}(1.11)$ & DMA & 2.5 & 99 & 37600 & 1.29 & $34: 239$ (PS: PDMA) \\
\hline
\end{tabular}

${ }^{\mathrm{a}}[\text { monomer }]_{0}:[\text { Macro-CTA }]_{0}:[\mathrm{AIBN}]_{0}=800: 1: 0.2$; temperature was set at $65^{\circ} \mathrm{C}$.

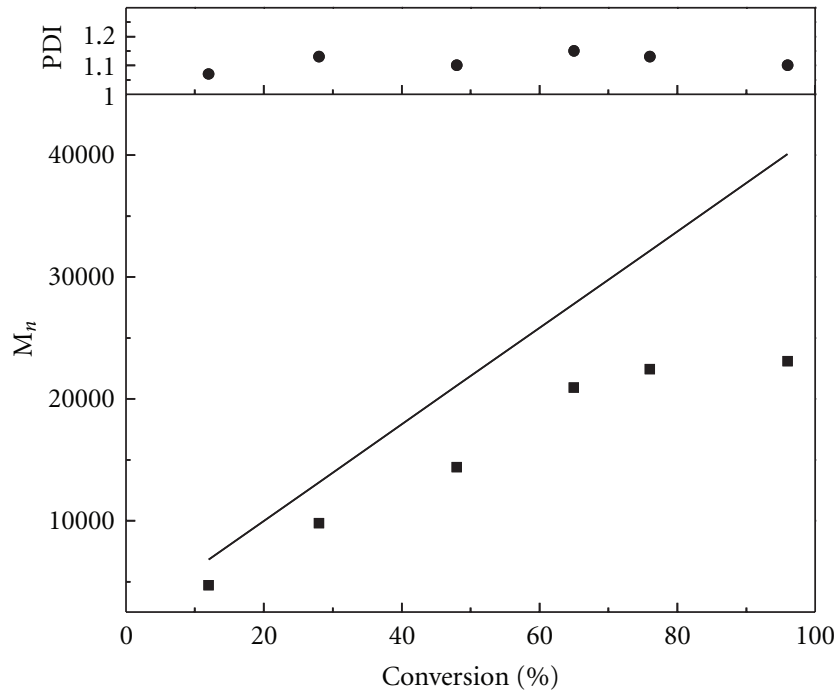

Figure 4: Number-average molecular weight $\left(M_{n}\right.$ by GPC: black square) and polydispersity index (PDI: black circle ) against monomer conversion for RAFT of DMA at $65^{\circ} \mathrm{C}$ with a ratio of $[\mathrm{DMA}]_{0}$ : $[\mathrm{CTA}-\mathrm{FBP}]_{0}:[\mathrm{AIBN}]_{0}=400: 1: 0.2$. Line indicates the theoretical molecular weight.

in Figure 3. As shown, the polymerization followed first order kinetics suggesting a constant concentration of active species throughout the polymerization. Molecular weights and molecular weight distributions of the polymers produced at each time interval were characterized by GPC. These traces clearly show an increment in the molecular weight proportional to the polymerization time and the polydispersity remained below 1.20 throughout the polymerization (Figure 4). As mentioned briefly previously, the comparison between the apparent molecular weight of the polymers and theoretical values in Figure 4 indicates GPC analysis provided underestimated molecular weights, especially at higher monomer conversion. Several possible reasons may account for this phenomenon: (1) polystyrene standards were used for molecular weight calculation, (2) star polymers usually have smaller hydrodynamic volumes than linear polymers of the same molecular weight [36], and (3) it is also possible that some side reactions such as termination occurred at high monomer conversions. Overall, the first order kinetics together with the controlled molecular weight and narrow polydispersity of the resultant polymers suggests the RAFT polymerization of DMA using CTA-FBP to be a controlled route towards the synthesis of these star polymers.

3.3. Synthesis of Porphyrin Cored Block Copolymers. The living characteristics of the polymerization provided an opportunity to synthesize star block copolymers. As shown in Scheme 2, $\mathrm{P}$-(PDMA) ${ }_{4}$ (or $\left.\mathrm{P}-(\mathrm{PS})_{4}\right)$ can be used as macro-CTA to initiate the RAFT polymerisation of St (or DMA) for the preparation of amphiphilic porphyrin cored star block copolymers. Successful chain extension upon the addition of the second monomers was confirmed by GPC characterization. Two typical GPC traces for P-(PDMA) 4 and P-(PDMA-PS $)_{4}$ are compared in Figure 5. It is clearly demonstrated that the overall molecular weight shifts to a higher value suggesting an efficient chain extension of the macro-CTA. ${ }^{1} \mathrm{H}$-NMR characterization indicated that the polymers consist of both PS and PDMA segments (see Figure 6). The block ratio can be estimated from the integration of the appropriate peaks due to PS and PDMA. Using a similar approach, P-(PS-PDMA) $)_{4}$ was also prepared. The detailed characterization of these two block copolymers is summarized in Table 2.

3.4. Self-Assembly of Porphyrin Cored Star Block Copolymers. As the optical properties of free-base porphyrin are very sensitive to its aggregation structure and external proton and metal ions, self-assembly of porphyrin star polymers may lead to micelles with different optical properties. Further, porphyrin can be used as a probe to investigate the supramolecular structures of the micelles. We prepared micelles in methanol using both $\mathrm{P}-\left(\mathrm{PDMA}_{96}-\mathrm{PS}_{33}\right)_{4}$ and $\mathrm{P}-$ $\left(\mathrm{PS}_{34}-\mathrm{PDMA}{ }_{239}\right)_{4}$. Methanol is a selective solvent for PDMA, in which PS aggregates into the cores and PDMA forms the coronas. The resulting micelles were characterized using TEM, with all samples negatively stained. As shown in the images (Figure 7), both polymers aggregated into spheres with diameters in the range of $20 \mathrm{~nm}$ to $60 \mathrm{~nm}$. P-(PDMA96$\left.\mathrm{PS}_{33}\right)_{4}$ micelles (see Figure $7(\mathrm{a})$ ) are smaller relative to those of P-( $\left.\mathrm{PS}_{34}-\mathrm{PDMA}_{239}\right)_{4}$ (see Figure $7(\mathrm{~b})$ ), probably because the molecular weight of the first polymer is lower. The micelle solutions were also characterized using DLS. This characterization indicated that $\mathrm{P}-\left(\mathrm{PS}_{34}-\mathrm{PDMA}_{239}\right)_{4}$ micelles have a diameter of $56 \mathrm{~nm}$ in solution, which is consistent with the TEM data (see Figure 7(b)). However, for P-(PDMA96$\left.\mathrm{PS}_{33}\right)_{4}$ micelles, DLS revealed an average diameter of $100 \mathrm{~nm}$, which is much larger than that found in the TEM analysis (Figure 7(a)). This conflicting result between DLS and TEM suggests a small number of larger aggregates were formed in solution, as DLS normally emphasizes larger particles. The different self-assembly behavior as detected by DLS may also relate to the structure of the polymers. Based on the architectures of the polymers, we can assume that, as shown in Scheme 3, flower and star-like micelles were formed from $\mathrm{P}-\left(\mathrm{PDMA}_{96}-\mathrm{PS}_{33}\right)_{4}$ and $\mathrm{P}-\left(\mathrm{PS}_{34}-\mathrm{PDMA}_{239}\right)_{4}$, respectively. In the formation of flower-like micelles, it often happens that 

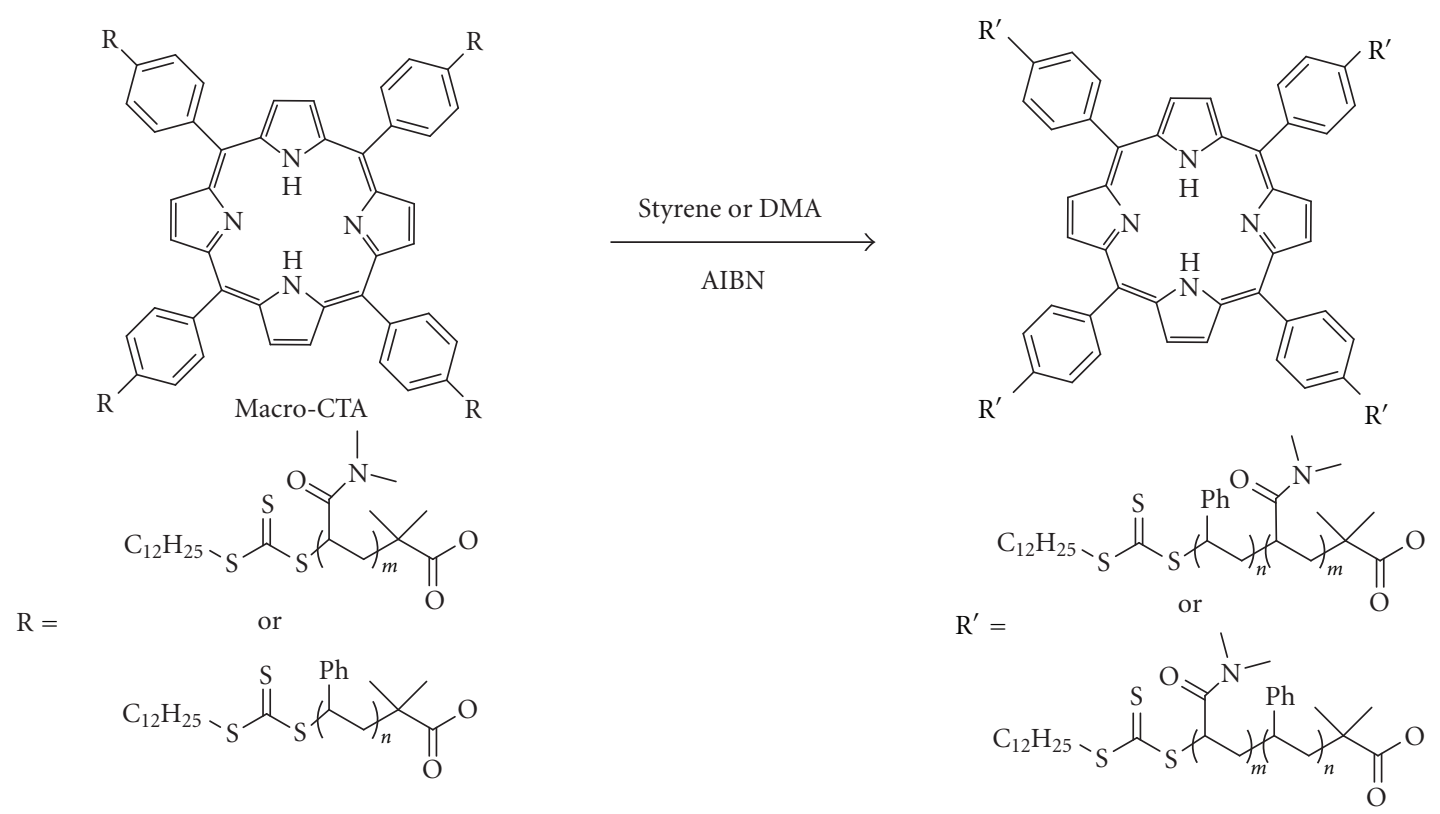

Scheme 2: Synthesis of porphyrin star block copolymers using porphyrin star homopolymers as macro-CTA.
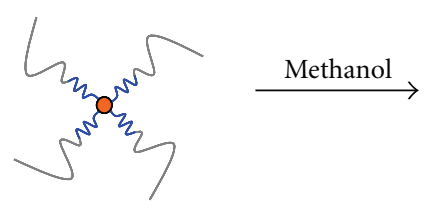

$\mathrm{P}-\left(\mathrm{PDMA}_{96}-\mathrm{PS}_{33}\right)_{4}$
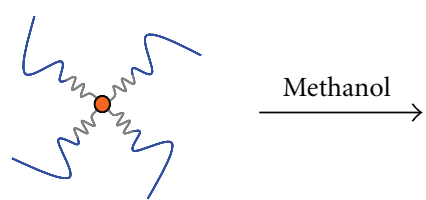

$$
\mathrm{P}-\left(\mathrm{PS}_{34}-\mathrm{PDMA}_{239}\right)_{4}
$$

— PS

- PDMA

- Free-base porphyrin

Scheme 3: Flower-like micelles and star-like micelles self-assembled from P-( $\left.\mathrm{PDMA}_{96}-\mathrm{PS}_{33}\right)_{4}$ and $\mathrm{P}-\left(\mathrm{PS}_{34}-\mathrm{PDMA}_{239}\right)_{4}$, respectively.

one molecule may bridge two micelles inducing micellemicelle aggregates, which may be a reason for the formation of a small amount of large aggregates in the P-(PDMA ${ }_{96}^{-}$ $\left.\mathrm{PS}_{33}\right)_{4}$ system.

Following TEM and DLS characterization, we investigated the structure-related optical properties of the micelles and confirmed the formation of the two types of micelles depicted in Scheme 3. UV-vis spectroscopy was used for the primary investigation. Unimers of both polymers in THF exhibited a strong absorption at $416 \mathrm{~nm}$ which is a characteristic of the Soret band for porphyrin units. Upon micellization in methanol, the Soret band shifted to $420 \mathrm{~nm}$ for $\mathrm{P}-\left(\mathrm{PS}_{34}-\mathrm{PDMA}_{239}\right)_{4}$ micelles, suggesting that porphyrins were indeed embedded in the cores of the micelles [45]. In contrast, the Soret band for P-( $\left.\mathrm{PDMA}_{96}-\mathrm{PS}_{33}\right)_{4}$ micelles in methanol remained at $416 \mathrm{~nm}$, suggesting that the micellization of this polymer did not perturb the porphyrin electronic transition. The segregation of porphyrins as a result of flower-like structures is a likely factor in this phenomenon.

The structure-related optical properties of the micelles were further studied using spectrophotometric titration. Depending on the position of porphyrin in the micelles, a structure-related optical response upon adding acid would be expected. As such, star-like and flower-like micelles should be distinguishable. We first performed UV-vis spectrophotometric titrations of $\mathrm{P}-\left(\mathrm{PDMA}_{96}-\mathrm{PS}_{33}\right)_{4}$ and $\mathrm{P}-\left(\mathrm{PS}_{34}-\right.$ $\left.\mathrm{PDMA}_{239}\right)_{4}$ micelles, respectively, against $\mathrm{HCl}$ with the spectra illustrated in Figure 8. As we can see from the Figures $8(\mathrm{a})$ and $8(\mathrm{~b})$, the Soret band and Q-band for the porphyrin in both micelles changed remarkably with the amount of added HCl. For example, the absorption of the Soret band of free-base porphyrin decreased with a concurrent absorbance enhancement at $442 \mathrm{~nm}$ due to protonated porphyrin. This result suggests that porphyrin either in the core or the periphery of the aggregates can be accessed by protons. In a quantitative sense, however, differences in the optical response behaviour are observed. These difference can be appreciated by comparing the absorbance changes at $442 \mathrm{~nm}$ as a function of the amount of proton added during the titration (see Figure 9). As shown in the figure, a relatively large amount of $\mathrm{H}^{+}$was required to protonate the porphyrin in $\mathrm{P}-\left(\mathrm{PS}_{34}-\mathrm{PDMA}_{239}\right)_{4}$ micelles, although the porphyrin concentrations in $\mathrm{P}-\left(\mathrm{PS}_{34}-\mathrm{PDMA}_{239}\right)_{4}$ micelles (ca. $\left.9 \times 10^{-7} \mathrm{M}\right)$ is lower than that in the $\mathrm{P}-\left(\mathrm{PDMA}_{96}-\mathrm{PS}_{33}\right)_{4}$ equivalents (ca. $2 \times 10^{-6} \mathrm{M}$ ). This comparison suggests $\mathrm{H}^{+}$ 


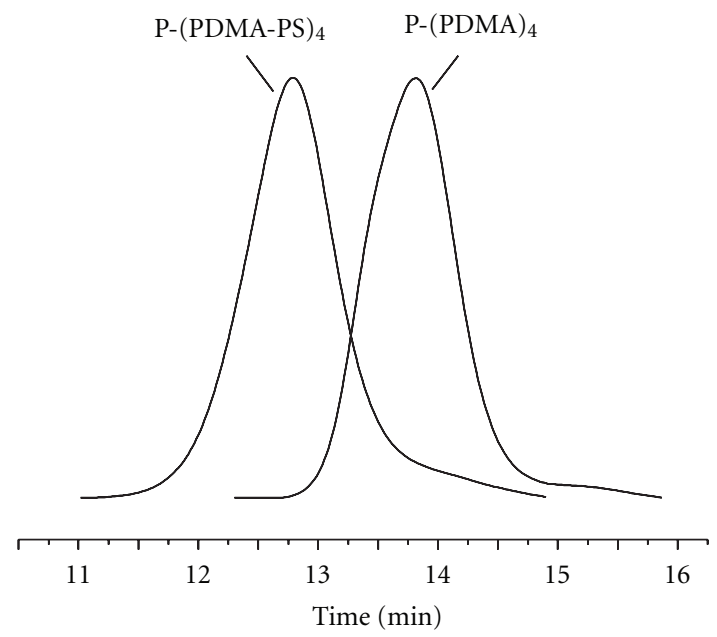

Figure 5: GPC traces for P-(PDMA-PS $)_{4}$ and P-(PDMA $)_{4}$. P-(PDMA-PS $)_{4}$ were synthesized through RAFT of St using P-(PDMA $)_{4}$ as Macro-CTA.

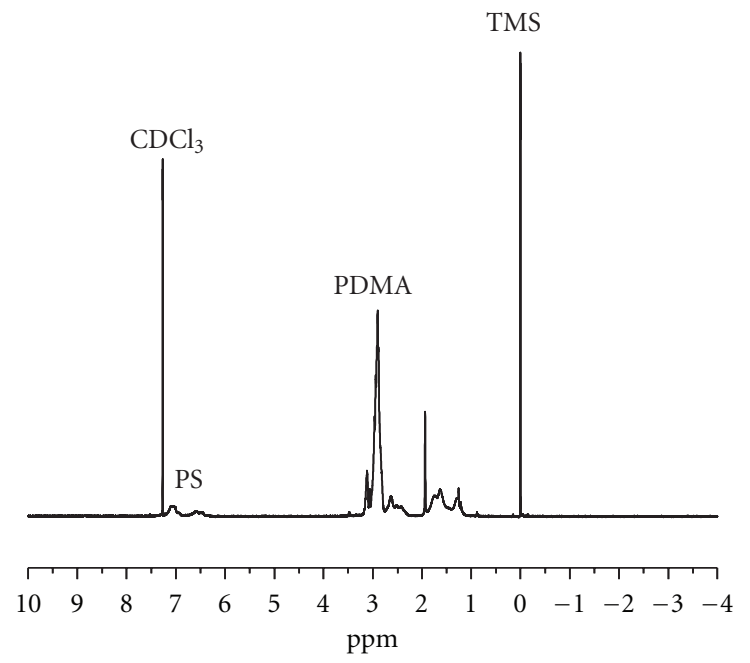

Figure 6: ${ }^{1} \mathrm{H}$ NMR spectrum for P-(PDMA-PS) $)_{4}$ star block copolymer.

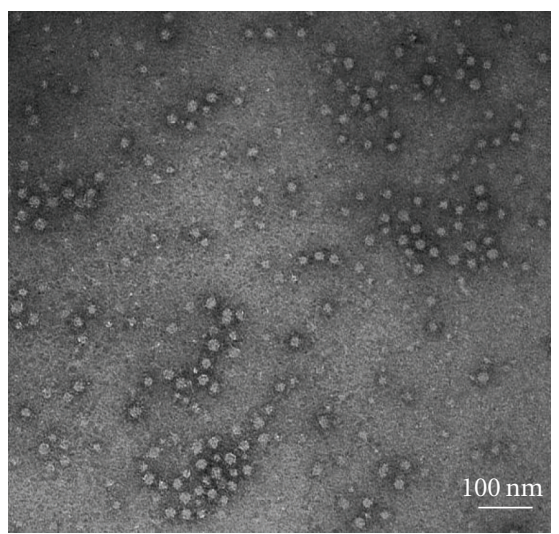

(a)

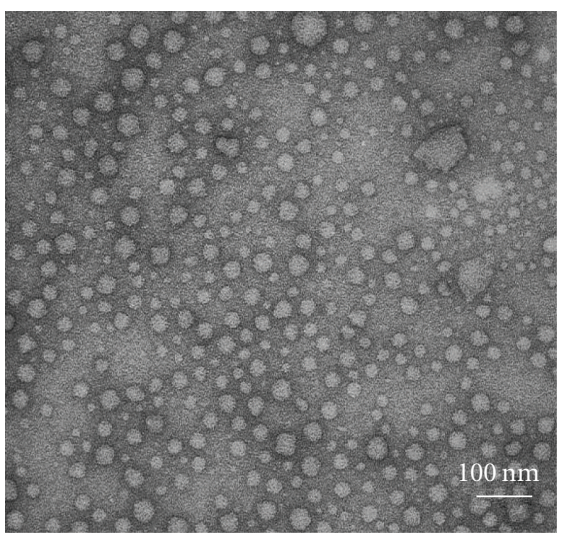

(b)

FIgURE 7: TEM images for the micellar aggregates of P-(PDMA $\left.{ }_{96}-\mathrm{PS}_{33}\right)_{4}$ (a) and $\mathrm{P}-\left(\mathrm{PS}_{34}-\mathrm{PDMA}_{239}\right)_{4}$ (b). Samples were prepared from methanol solutions and negative stained using uranyl acetate. 


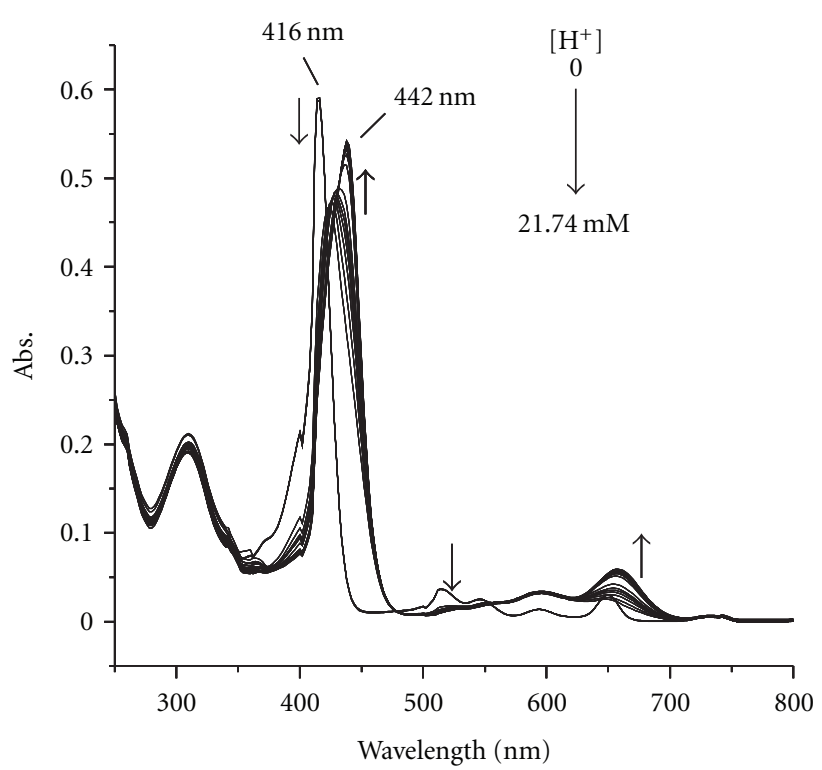

(a)

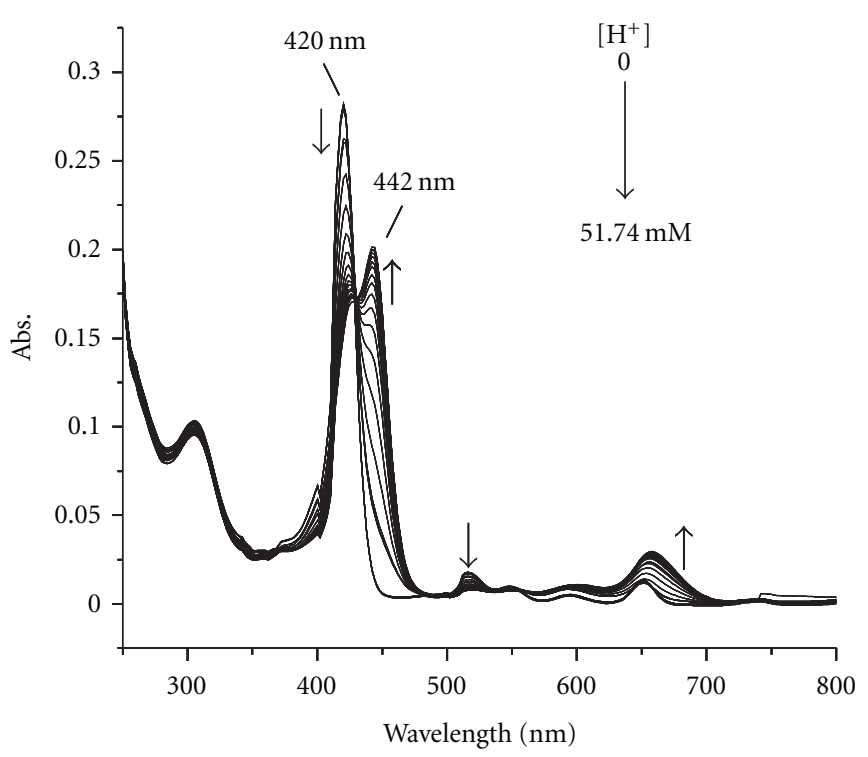

(b)

Figure 8: UV-vis spectrophotometric titration. (a) Adding $\mathrm{H}^{+}$into $\mathrm{P}-\left(\mathrm{PDMA}_{96}-\mathrm{PS}_{33}\right)_{4}$ flower-like micelles. (b) Adding $\mathrm{H}^{+}$into $\mathrm{P}-\left(\mathrm{PS}_{34}-\right.$ $\left.\mathrm{PDMA}_{239}\right)_{4}$ star-like micelles.

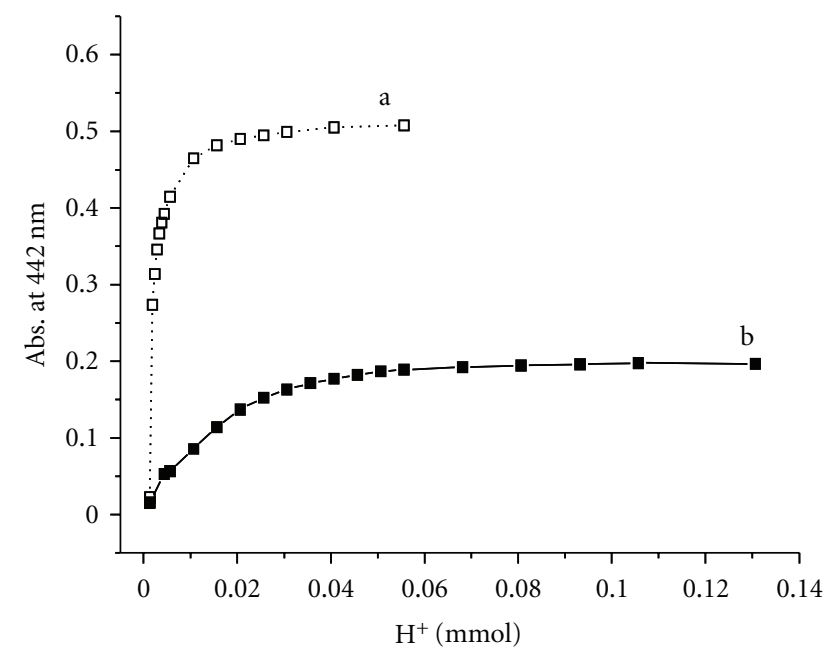

FIGURE 9: Plot of absorbance changes at $442 \mathrm{~nm}$ against the amount of $\mathrm{H}^{+}(\mathrm{mmol})$ added into P- $\left(\mathrm{PDMA}_{96}-\mathrm{PS}_{33}\right)_{4}$ (a) and $\mathrm{P}-\left(\mathrm{PS}_{34}-\mathrm{PD}\right.$ $\left.\mathrm{MA}_{239}\right)_{4}$ micelles (b).

had more difficulty accessing the porphyrin functionality in the $\mathrm{P}-\left(\mathrm{PS}_{34}-\mathrm{PDMA}_{239}\right)_{4}$ star-like micelles relative to the same functionality in the $\mathrm{P}-\left(\mathrm{PDMA}_{96}-\mathrm{PS}_{33}\right)_{4}$ flower-like aggregates. It was possible to entirely prevent protonation of the core porphyrin by transferring the micelles from the original methanol solution to water through a dialysis process (see Figure 10). This observation was probably due to tighter packing of PS chains in water compared to in methanol. Overall, these experiments demonstrated that porphyrin can be use to probe subtle change in micellar structure.

These micelle structure-related optical properties were more obvious when fluorescence titrations of the micelles

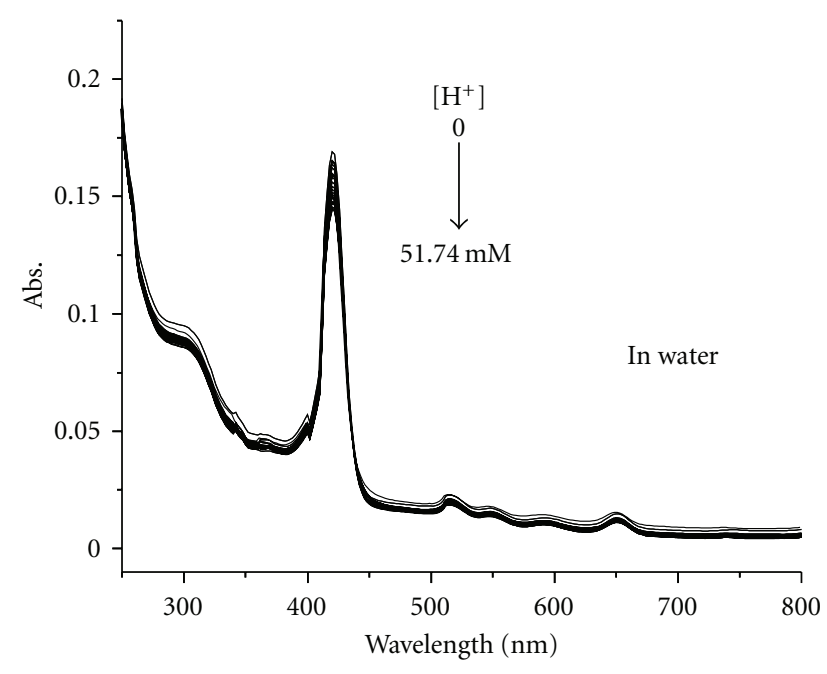

FIgure 10: UV-vis spectrophotometric titration of $\mathrm{P}-\left(\mathrm{PS}_{34}-\mathrm{PDM}\right.$ $\left.\mathrm{A}_{239}\right)_{4}$ star-like micelles in water.

in methanol using $\mathrm{NaI}$ as quencher were performed. As shown in Figure 11(a), the fluorescence intensity of P$\left(\mathrm{PDMA}_{96}-\mathrm{PS}_{33}\right)_{4}$ flower-like micelles at $651 \mathrm{~nm}$ dropped rapidly with increasing amount of NaI. On the contrary, however, for $\mathrm{P}-\left(\mathrm{PS}_{34}-\mathrm{PDMA}_{239}\right)_{4}$ star-like micelles, under the same conditions, there is very little change in the intensity of the fluorescent signal (see Figure 11(b)), indicating NaI did not effectively quench the photoluminescence of porphyrins embedded inside the cores of the micelles in methanol.

3.5. Metallization of Porphyrin Micelles. It is well-known that porphyrins are capable of binding metal ions and that the properties of metalloporphyrins are strongly related to the type of metal coordinated. We explored this possibility of 

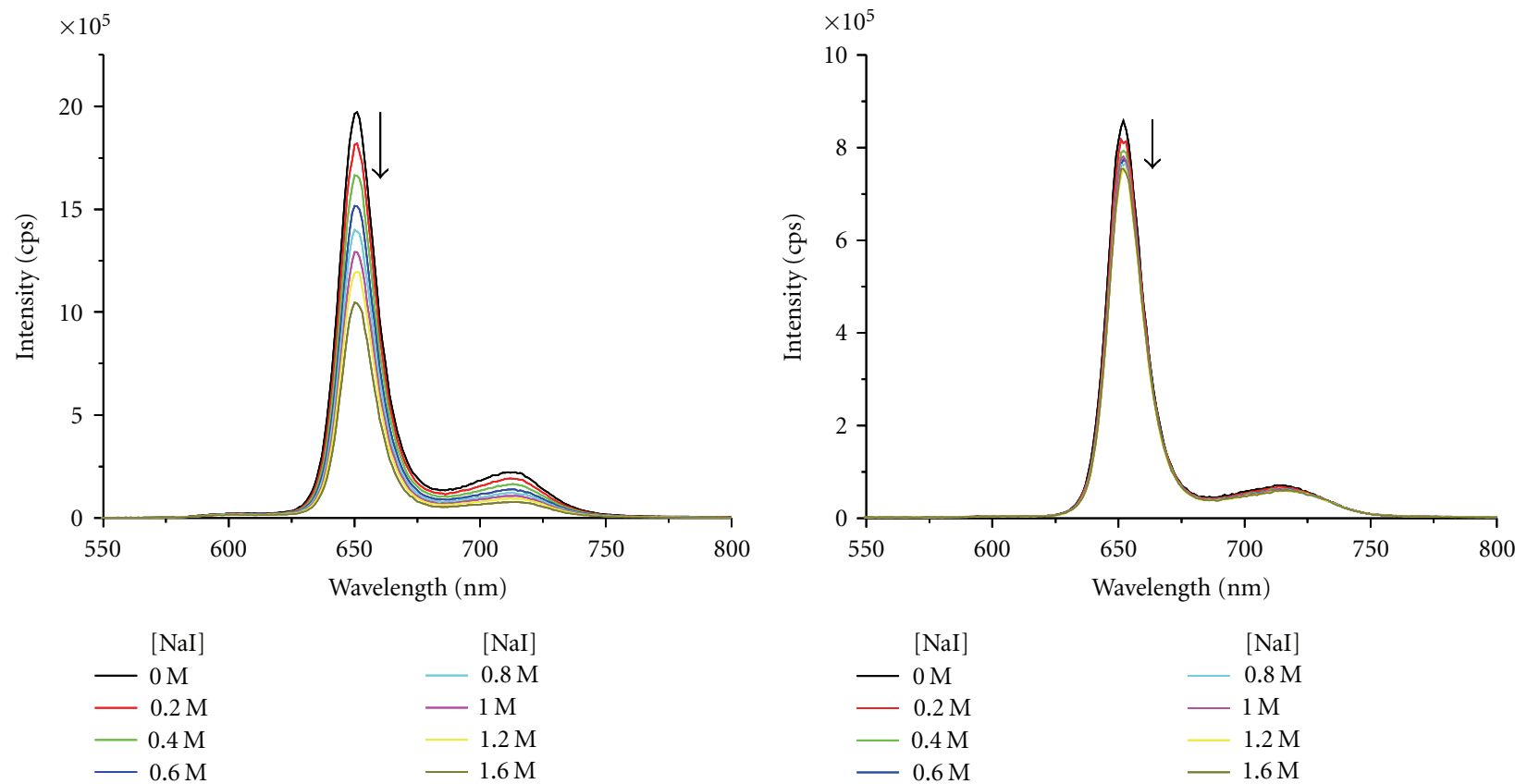

(a)

(b)

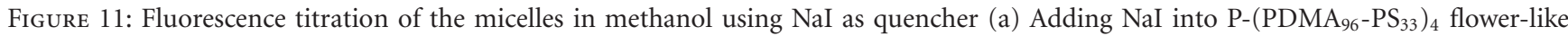
micelles. (b) Adding $\mathrm{NaI}$ into $\mathrm{P}-\left(\mathrm{PS}_{34}-\mathrm{PDMA}_{239}\right)_{4}$ star-like micelles.

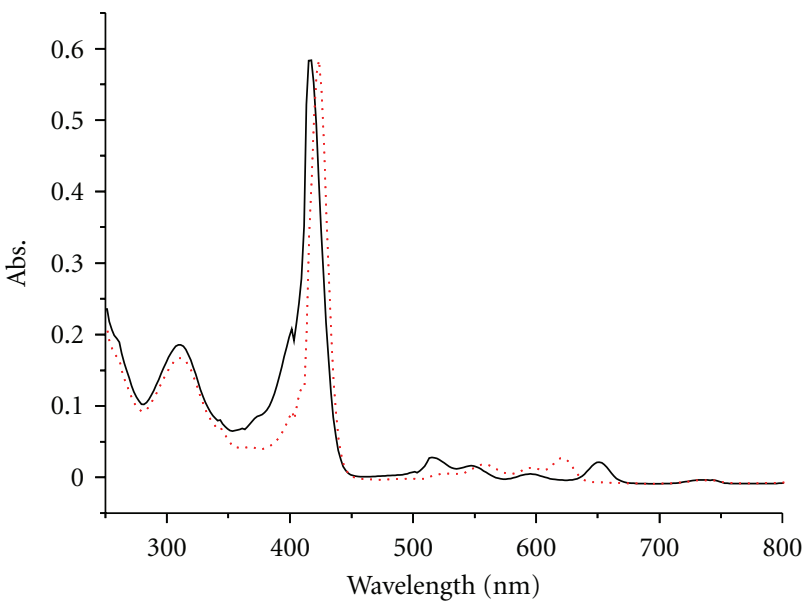

- P-(PDMA-PS) $)_{4}$ micelles in $\mathrm{CH}_{3} \mathrm{OH}$ 17 hours later after addition of $\mathrm{Zn}^{2+}$

(a)

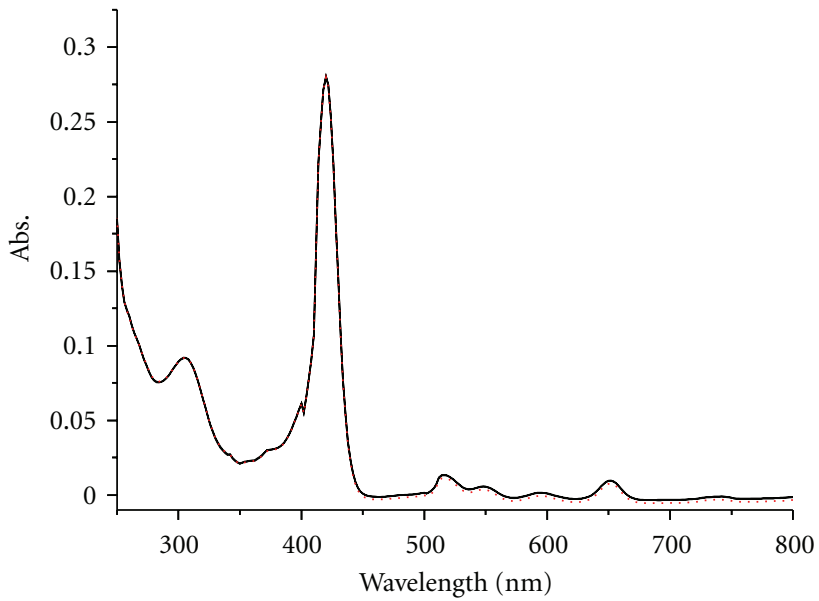

- P-(PDMA-PS $)_{4}$ micelles in $\mathrm{CH}_{3} \mathrm{OH}$ 72 hours later after addition of $\mathrm{Zn}^{2+}$

(b)

FIGURE 12: UV-vis spectra of the micelles in methanol in the absence and in the presence of $\mathrm{Zn}^{2+}\left(5 \times 10^{-4} \mathrm{M}\right)$. (a) P-(PDMA $\left.{ }_{96}-\mathrm{PS}_{33}\right)_{4}$ micelles. (b) P-( $\left.\mathrm{PS}_{34}-\mathrm{PDMA}_{239}\right)_{4}$ micelles.

functionalizing our porphyrin containing polymers using $\mathrm{Zn}^{2+}$ metal ions. Zinc acetate $\left(5 \times 10^{-4} \mathrm{M}\right.$ of $\mathrm{Zn}^{2+}$ in the quartz cell) was introduced into the $\mathrm{P}-\left(\mathrm{PDMA}_{96}-\mathrm{PS}_{33}\right)_{4}$ and $\mathrm{P}-\left(\mathrm{PS}_{34}-\mathrm{PDMA}_{239}\right)_{4}$ micelles $(0.1 \mathrm{mg} / \mathrm{mL})$ at room temperature. Distinguishable UV-vis spectral changes were observed within 17 hours for $\mathrm{P}-\left(\mathrm{PDMA}_{96}-\mathrm{PS}_{33}\right)_{4}$ flower-like micelles due to the formation of a zinc porphyrin complex (see Figure 12(a)). As a result of the metal coordination, the micelles could be observed in TEM directly without negative staining (see Figure 13). On the contrary, the UV-vis absorption of $\mathrm{P}-\left(\mathrm{PS}_{34}-\mathrm{PDMA}_{239}\right)_{4}$ star micelles remained the same after three days, suggesting it is difficult to coordinate $\mathrm{Zn}^{2+}$ with porphyrin trapped in the micelle core. Overall, the metal coordination chemistry observed here as a function of micellar structure offers many possibilities worthy of further exploration, such as in sensors and heavy metal assays. 


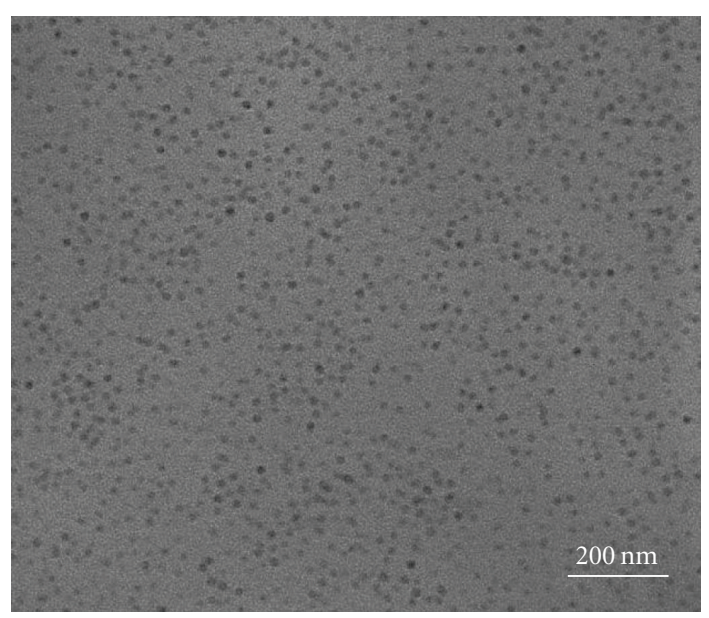

FIgURE 13: TEM image for Zinc coordinated P-(PDMA96 $\left.-\mathrm{PS}_{33}\right)_{4}$ micelles. Sample was prepared from methanol solution without staining.

\section{Conclusions}

We have demonstrated that RAFT, as a metal-free living system compatible with a wide range of monomers, is a powerful and efficient tool for the design and synthesis of free-base porphyrin polymers. The self-assembly of synthesized star block copolymers of P-(PDMA96 $\left.-\mathrm{PS}_{33}\right)_{4}$ and $\mathrm{P}-\left(\mathrm{PS}_{34}-\mathrm{PDMA}_{239}\right)_{4}$ in methanol, a selective solvent for PDMA, led to spherical micelles with the porphyrin positioned either in the core or periphery of the micelles depending on the polymer architecture. The structures were characterized using TEM and DLS. UV-vis and fluorescence studies indicated the micelles possess a structure-related optical behaviour and coordination chemistry, which should prove useful for micelle studies and material exploration in the future.

\section{Acknowledgments}

This work was financially supported by The Engineering and Physical Sciences Research Council, UK (EPSRC). X. S. Wang thanks the EPSRC for the award of a Roberts Fellowship. GQF and R. McHale thank the EPSRC for PDRA fellowships. F. Guodong Liang and Tanapak Metanawin are acknowledged for TEM experiments.

\section{References}

[1] J. A. A. W. Elemans, R. van Hameren, R. J. M. Nolte, and A. E. Rowan, "Molecular materials by self-assembly of porphyrins, phthalocyanines, and perylenes," Advanced Materials, vol. 18, no. 10, pp. 1251-1266, 2006.

[2] T. S. Balaban, "Tailoring porphyrins and chlorins for selfassembly in biomimetic artificial antenna systems," Accounts of Chemical Research, vol. 38, no. 8, pp. 612-623, 2005.

[3] Y. Kim, M. F. Mayer, and S. C. Zimmerman, "A new route to organic nanotubes from porphyrin dendrimers," Angewandte Chemie-International Edition, vol. 42, no. 10, pp. 1121-1126, 2003.
[4] L. J. Twyman and Y. Ge, "Porphyrin cored hyperbranched polymers as heme protein models," Chemical Communications, no. 15, pp. 1658-1660, 2006.

[5] B. Li, X. Xu, M. Sun et al., "Porphyrin-cored star polymers as efficient nondoped red light-emitting materials," Macromolecules, vol. 39, no. 1, pp. 456-461, 2006.

[6] T. Imaoka, R. Tanaka, S. Arimoto, M. Sakai, M. Fujii, and K. Yamamoto, "Probing stepwise complexation in phenylazomethine dendrimers by a metallo-porphyrin core," Journal of the American Chemical Society, vol. 127, no. 40, pp. 13896-13905, 2005.

[7] F. Loiseau, S. Campagna, A. Hameurlaine, and W. Dehaen, "Dendrimers made of porphyrin cores and carbazole chromophores as peripheral units. Absorption spectra, luminescence properties, and oxidation behavior," Journal of the American Chemical Society, vol. 127, no. 32, pp. 11352-11363, 2005.

[8] X. Zheng, I. R. Oviedo, and L. J. Twyman, "Pseudogenerational effects observed for a series of hyperbranched polymers when applied as epoxidation catalysts," Macromolecules, vol. 41, no. 21, pp. 7776-7779, 2008.

[9] S. Hecht, H. Ihre, and J. M. J. Fréchet, "Porphyrin core star polymers: synthesis, modification, and implication for site isolation," Journal of the American Chemical Society, vol. 121, no. 39, pp. 9239-9240, 1999.

[10] S. Hecht, N. Vladimirov, and J. M. J. Fréchet, "Encapsulation of functional moieties within branched star polymers: effect of chain length and solvent on site isolation," Journal of the American Chemical Society, vol. 123, no. 1, pp. 18-25, 2001.

[11] R. H. Jin, "Controlled location of porphyrin in aqueous micelles self-assembled from porphyrin centered amphiphilic star poly(oxazolines)," Advanced Materials, vol. 14, no. 12, pp. 889-892, 2002.

[12] R. H. Jin, "Self-assembly of porphyrin-centered amphiphilic star block copolymer into polymeric vesicular aggregates," Macromolecular Chemistry and Physics, vol. 204, no. 3, pp. 403-409, 2003.

[13] R. H. Jin, "Water soluble star block poly(oxazoline) with porphyrin label: a unique emulsion and its shape direction," Journal of Materials Chemistry, vol. 14, no. 3, pp. 320-327, 2004.

[14] F. de Loos, I. C. Reynhout, J. J. L. M. Cornelissen, A. E. Rowan, and R. J. M. Nolte, "Construction of functional porphyrin polystyrene nano-architectures by ATRP," Chemical Communications, no. 1, pp. 60-62, 2005.

[15] J. B. Beil and S. C. Zimmerman, "Synthesis of nanosized "cored" star polymers," Macromolecules, vol. 37, no. 3, pp. 778-787, 2004.

[16] L. R. H. High, S. J. Holder, and H. V. Penfold, "Synthesis of star polymers of styrene and alkyl (meth)acrylates from a porphyrin initiator core via ATRP,” Macromolecules, vol. 40, no. 20, pp. 7157-7165, 2007.

[17] W. R. Dichtel, K. Y. Baek, J. M. J. Fréchet, I. B. Rietveld, and S. A. Vinogradov, "Amphiphilic diblock star polymer catalysts via atom transfer radical polymerization," Journal of Polymer Science, Part A: Polymer Chemistry, vol. 44, no. 17, pp. 49394951, 2006.

[18] D. Vlascici, E. F. Cosma, E. M. Pica et al., "Free base porphyrins as ionophores for heavy metal sensors," Sensors, vol. 8, no. 8, pp. 4995-5004, 2008.

[19] J. Chiefari, Y. K. Chong, F. Ercole et al., "Living free-radical polymerization by reversible addition-fragmentation chain transfer: the RAFT process," Macromolecules, vol. 31, no. 16, pp. 5559-5562, 1998. 
[20] C. Barner-Kowollik, T. P. Davis, J. P. A. Heuts, M. H. Stenzel, P. Vana, and M. Whittaker, "RAFTing down under: tales of missing radicals, fancy architectures, and mysterious holes," Journal of Polymer Science, Part A: Polymer Chemistry, vol. 41, no. 3, pp. 365-375, 2003.

[21] G. Moad, E. Rizzardo, and S. H. Thang, "Living radical polymerization by the RAFT process," Australian Journal of Chemistry, vol. 58, no. 6, pp. 379-410, 2005.

[22] G. Moad, E. Rizzardo, and S. H. Thang, "Living radical polymerization by the RAFT process - a first update," Australian Journal of Chemistry, vol. 59, no. 10, pp. 669-692, 2006.

[23] A. B. Lowe and C. L. McCormick, "Reversible additionfragmentation chain transfer (RAFT) radical polymerization and the synthesis of water-soluble (co)polymers under homogeneous conditions in organic and aqueous media," Progress in Polymer Science, vol. 32, no. 3, pp. 283-351, 2007.

[24] C. Boyer, M. H. Stenzel, and T. P. Davis, "Building nanostructures using RAFT polymerization," Journal of Polymer Science, Part A: Polymer Chemistry, vol. 49, no. 3, pp. 551-595, 2011.

[25] M. H. Stenzel, T. P. Davis, and C. Barner-Kowollik, "Poly(vinyl alcohol) star polymers prepared via MADIX/RAFT polymerisation," Chemical Communications, vol. 10, no. 13, pp. 15461547, 2004.

[26] V. Darcos, A. Duréault, D. Taton et al., "Synthesis of hybrid dendrimer-star polymers by the RAFT process," Chemical Communications, vol. 10, no. 18, pp. 2110-2111, 2004.

[27] J. Bernard, A. Favier, L. Zhang et al., "Poly(vinyl ester) star polymers via xanthate-mediated living radical polymerization: from poly(vinyl alcohol) to glycopolymer stars," Macromolecules, vol. 38, no. 13, pp. 5475-5484, 2005.

[28] J. Bernard, X. Hao, T. P. Davis, C. Barner-Kowollik, and M. H. Stenzel, "Synthesis of various glycopolymer architectures via RAFT polymerization: from block copolymers to stars," Biomacromolecules, vol. 7, no. 1, pp. 232-238, 2006.

[29] A. J. Inglis, S. Sinnwell, T. P. Davis, C. Barner-Kowollik, and M. H. Stenzel, "Reversible addition fragmentation chain transfer (RAFT) and hetero-diels-alder chemistry as a convenient conjugation tool for access to complex macromolecular designs," Macromolecules, vol. 41, no. 12, pp. 4120-4126, 2008.

[30] G. Hart-Smith, H. Chaffey-Millar, and C. Barner-Kowollik, "Living star polymer formation: detailed assessment of poly(acrylate) radical reaction pathways via ESI-MS," Macromolecules, vol. 41, no. 9, pp. 3023-3041, 2008.

[31] G. Johnston-Hall and M. J. Monteiro, "Diffusion controlled termination of linear polystyrene radicals in linear, 4-Arm, and 6-Arm star polymer matrices in dilute, semidilute, and concentrated solution conditions," Macromolecules, vol. 41, no. 3, pp. 727-736, 2008.

[32] R. T. A. Mayadunne, J. Jeffery, G. Moad, and E. Rizzardo, "Living free radical polymerization with reversible addition-fragmentation chain transfer (RAFT polymerization): approaches to star polymers," Macromolecules, vol. 36, no. 5, pp. 15051513, 2003.

[33] M. Stenzel-Rosenbaum, T. P. Davis, V. Chen, and A. G. Fane, "Star-polymer synthesis via radical reversible additionfragmentation chain-transfer polymerization," Journal of Polymer Science, Part A: Polymer Chemistry, vol. 39, no. 16, pp. 2777-2783, 2001.

[34] H. Chaffey-Millar, M. H. Stenzel, T. P. Davis, M. L. Coote, and C. Barner-Kowollik, "Synthesis and degradation behaviour of cyclic poly(ع-caprolactone)," Macromolecules, vol. 39, pp. 6406-6419, 2006.
[35] C. Barner-Kowollik, T. P. Davis, and M. H. Stenzel, "Synthesis of star polymers using RAFT polymerization: what is possible?" Australian Journal of Chemistry, vol. 59, no. 10, pp. 719727, 2006.

[36] H. Mori, H. Ookuma, and T. Endo, "Poly(N-vinylcarbazole) star polymers and amphiphilic star block copolymers by xanthate-mediated controlled radical polymerization," Macromolecules, vol. 41, no. 19, pp. 6925-6934, 2008.

[37] D. Boschmann and P. Vana, "Z-RAFT star polymerizations of acrylates: star coupling via intermolecular chain transfer to polymer," Macromolecules, vol. 40, no. 8, pp. 2683-2693, 2007.

[38] J. T. Lai, D. Filla, and R. Shea, "Functional polymers from novel carboxyl-terminated trithiocarbonates as highly efficient RAFT agents," Macromolecules, vol. 35, no. 18, pp. 6754-6756, 2002.

[39] J. Hentschel, K. Bleek, O. Ernsty, J. F. Lutz, and H. G. Börner, "Easy access to bioactive peptide-polymer conjugates via RAFT," Macromolecules, vol. 41, no. 4, pp. 1073-1075, 2008.

[40] Z. An, Q. Shi, W. Tang, C. K. Tsung, C. J. Hawker, and G. D. Stucky, "Facile RAFT precipitation polymerization for the microwave-assisted synthesis of well-defined, double hydrophilic block copolymers and nanostructured hydrogels," Journal of the American Chemical Society, vol. 129, no. 46, pp. 14493-14499, 2007.

[41] J. N. Cambre, D. Roy, S. R. Gondi, and B. S. Sumerlin, "Facile strategy to well-defined water-soluble boronic acid (co)polymers," Journal of the American Chemical Society, vol. 129, no. 34, pp. 10348-10349, 2007.

[42] C. Cheng, G. Sun, E. Khoshdel, and K. L. Wooley, "Welldefined vinyl ketone-based polymers by reversible additionfragmentation chain transfer polymerization," Journal of the American Chemical Society, vol. 129, no. 33, pp. 10086-10087, 2007.

[43] H. Skaff and T. Emrick, "Reversible addition fragmentation chain transfer (RAFT) polymerization from unprotected cadmium selenide nanoparticles," Angewandte ChemieInternational Edition, vol. 43, no. 40, pp. 5383-5386, 2004.

[44] M. D. Rowe-Konopacki and S. G. Boyes, "Synthesis of surface initiated diblock copolymer brushes from flat silicon substrates utilizing the RAFT polymerization technique," Macromolecules, vol. 40, no. 4, pp. 879-888, 2007.

[45] Z. El-Hachemi, G. Mancini, J. M. Ribó, and A. Sorrenti, "Role of the hydrophobic effect in the transfer of chirality from molecules to complex systems: from chiral surfactants to porphyrin/surfactant aggregates," Journal of the American Chemical Society, vol. 130, no. 45, pp. 15176-15184, 2008. 

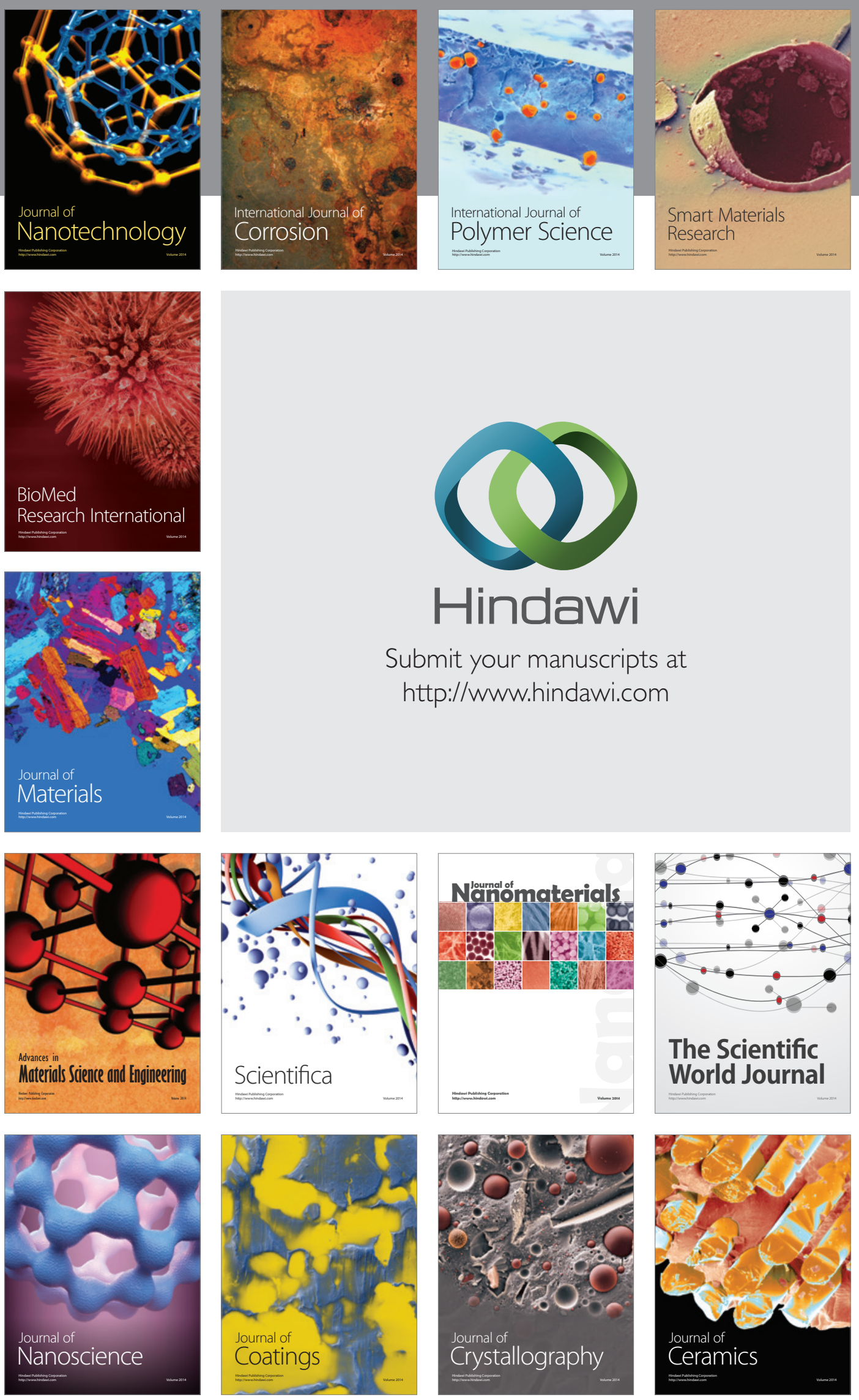

The Scientific World Journal

Submit your manuscripts at

http://www.hindawi.com

\section{World Journal}

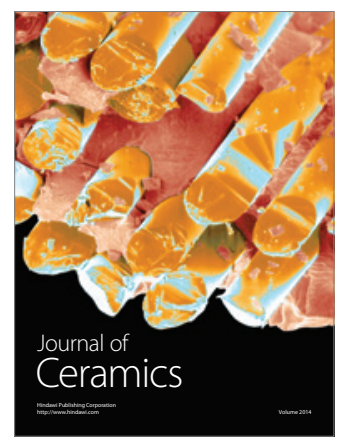

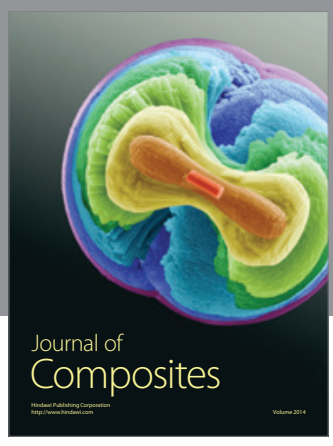
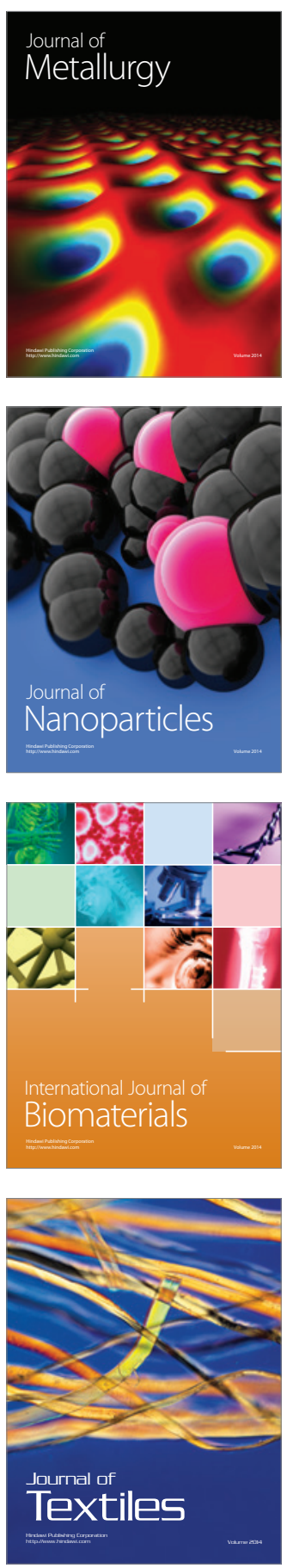